УДК 004.8

DOI https://doi.org/10.32838/2663-5941/2020.2-1/19

\title{
Марчук Г.В.
}

Державний університет «Житомирська політехніка»

Лисогор Ю.І.

Державний університет «Житомирська політехніка»

Мисливий М.В.

Державний університет «Житомирська політехніка»

\section{РОЗПІЗНАВАННЯ РОЗМІННИХ МОНЕТ УКРАЇНИ РІЗНОГО НОМІНАЛУ 3 ВИКОРИСТАННЯМ КОМП'ЮТЕРНОГО ЗОРУ}

У статті розглядається метод розпізнавання дрібних монет різного розміру, кольору та номіналу, які вилучаються з готівкового обігу Украйни. Основне завдання полягає в створенні програмного додатку для визначення номіналу, кількості монет і підрахунку їх суми з використанням комп 'ютерного зору. В роботі використовуються технології визначення об 'єктів за допомогою бібліотеки ОрепCV.

Одним із найефективніших методів пошуку аналітично заданих примітивів натепер є група методів, заснованих на ідеї перетворення Хафа (Hough transform). Перетворення Хафа-ие метод виявлення прямих і кривих ліній на напівтонових або кольорових зображеннях. Метод дозволяе вказати параметри сімейства кривих $i$ забезпечує пошук на зображенні множини кривих заданого сімейства. В роботі розглядається застосування алгоритму для пошуку кіл на зображенні. Загальний алгоритм роботи програмного додатку полягає у першочерговому визначенні типу монет, що знаходяться на зображенні.

Всі розмінні монети Украӥни випускаються в двох кольорах. Перша група - одна, дві, n’ять копійок - ие нержавіюча сталь або алюмінієвий сплав, який має сріблястий колір. Друга група - десять, двадиять n'ять, n'ятдесят копійок $i$ одна гривня. Це латунь, яка має жовтий (золотий) колір. Відштовхуючись від матеріалу, визначається їхній радіус за допомогою розробленого алгоритму.

Інформація про діаметр розмінних та обігових монет України взята на сайті Наџіонального Банку України. Правильна ідентифікація монет досягнута у 82,21\% випадків. Розглянуті в статті механізми розпізнавання і підрахунку монет можуть бути використані в різних фінансових установах. Створений програмний додаток дозволяє підрахувати суму монет дрібних номіналів, використовуючи фотографію; може розпізнавати монети різного номіналу та кольору старого та нового зразка.

Ключові слова: монета, комп'ютерний зір, алгоритм, коло, аналіз.

Постановка проблеми. В Україні з першого жовтня 2019 року вилучаються з обігу монети номіналом одна, дві та п'ять копійок. За даними НБУ на перше липня 2019 року в обігу знаходиться монет на 2,4 млрд грн (13,2 млрд шт.). Відповідно до Постанови правління НБУ № 82 «Про вилучення з готівкового обігу монет дрібних номіналів» монети можуть бути обміняні на діючі гроші протягом трьох років: до 30 вересня 2020 року в усіх відділеннях українських банків, а до 30 вересня 2022 року - тільки в Національному банку та в уповноважених фінансових установах. Щоб не витрачати час на такі неприбуткові операції, фінансові установи відмовляють користувачам в обміні монет. Для усунення цієї проблеми було прийнято рішення про створення програмного додатку, якій би зміг розпізнавати монети, їх кількість і номінал, видавати загальну суму.
Аналіз останніх досліджень і публікацій. Актуальність розробки програм із використанням комп'ютерного зору стає все більш незаперечною. Одним із найефективнішим методів, які застосовується під час аналізу та ідентифікації геометричних елементів в растрових зображеннях, $\epsilon$ перетворення Хафа. Однак розширення звичайного перетворення Хафа для ідентифікації кіл та еліпсів було обмежене повільною швидкістю та надмірною пам'яттю.

В роботі [1] представлені методи, спрямовані на підвищення ефективності та зменшення розміру пам'яті масиву акумуляторів. На основі цих методів потрібен лише двовимірний масив для виявлення кіл і еліпсів. В роботі “Automatic Coin Classification and Identifi-cation" [2] проведена класифікація об'єктів в умовах із великою кількістю класів, а також розпізнавання та ідентифікації 
окремих об'єктів з високою схожістю. Ідентифікація досліджується для ручних виготовлених старовинних монет. У статті [3] на підставі радіусу класифікуються монети різного номіналу. Результат експерименту показує, що перетворення Хафа $\epsilon$ ефективним інструментом для виявлення монет навіть при наявності шуму.

Постановка завдання - створити програмний додаток для визначення номіналу та кількості монет з використанням бібліотеки OpenCV та іiі вбудованої функції, яка реалізує алгоритм знаходження кіл на зображенні за допомогою перетворення Хафа. Інформація про діаметр розмінних та обігових монет України була отримана на сайті Національного Банку України.

Виклад основного матеріалу дослідження. Одним із найефективніших методів пошуку заданих примітивів натепер є група методів, заснованих на ідеї перетворення Хафа [4]. Автори застосовують принцип виявлення кола відомого радіуса. Математично коло можна представити такою формулою:

$$
\left(x-x_{0}\right)^{2}+\left(y-y_{0}\right)^{2}=R^{2},
$$

де $\left(x_{0}, y_{0}\right)$ - координати центру кола, a $\mathrm{R}$ радіус.

Для однозначного завдання кола необхідно знати координати центру і радіус (Рис. 1). Це призводить до збільшення простору Хафа на вимір. Завдання спрощується, якщо радіус кіл, які потрібно знайти, заздалегідь відомий. В такому випадку необхідно знаходити тільки координати центрів кіл.

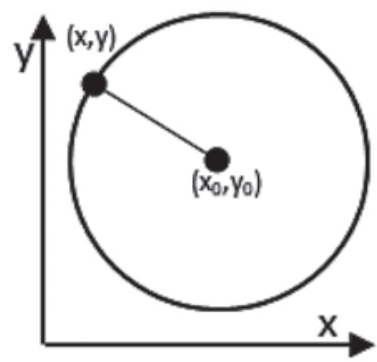

Рис. 1. Коло $з$ центром в точці $\left(x_{0}, y_{0}\right)$

Оскільки набір центрів всіх можливих кіл радіyса $\mathrm{R}$, які проходять через задану точку, утворює коло радіуса $\mathrm{R}$ навколо цієї точки, функція відгуку в перетворенні Хафа для пошуку кіл відомого розміру $є$ колом такого ж розміру 3 центром в голосуючій точці.

Найкраще рішення щодо положення центру в конкретній множині точок кола відповідає точці перетину максимальної кількості голосуючих кіл. Алгоритм пошуку кіл заданого радіуса на зображенні зводиться до «малювання» у фазовому просторі кіл з центрами в усіх непустих точках зображення і подальшого пошуку локальних максимумів простору Хафа (Рис. 2). При цьому можуть використовуватися різні методи аналізу простору параметрів, наприклад пошук фіксованої кількості локальних максимумів, порогова сегментація акумуляторної функції, що виключає пошук глобального максимуму акумуляторної функції [4].

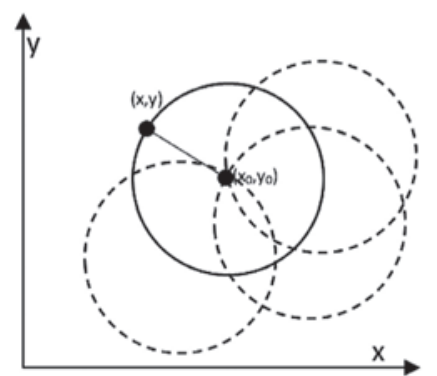

Рис. 2. Розпізнавання окружності методом Хафа

Загальний алгоритм роботи програми полягає в першочерговому визначенні типу монет, які знаходяться на зображенні. Після цього, відштовхуючись від матеріалу, визначається їхній радіус за допомогою алгоритму, схема якого зображена на Рисунку 3.

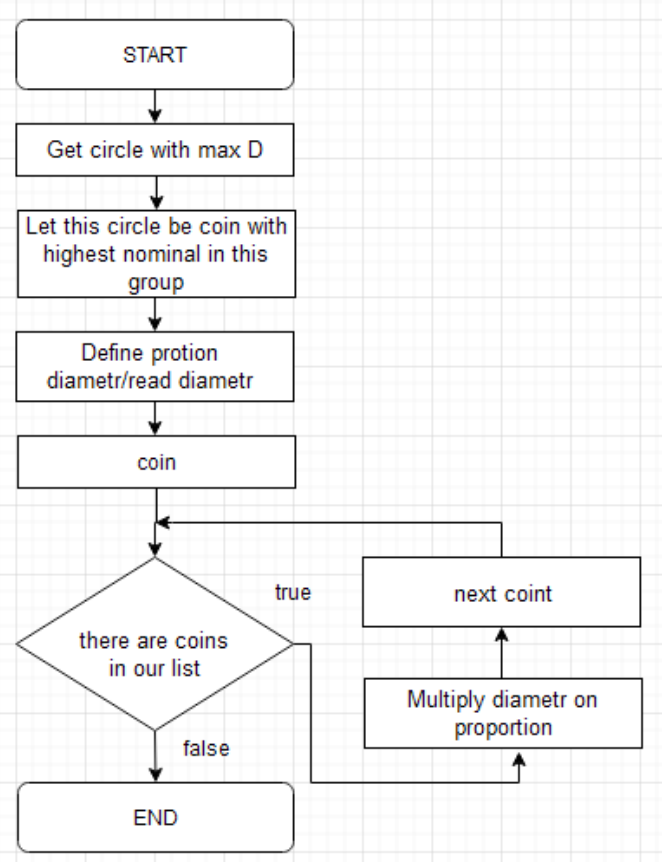

Рис. 3. Блок-схема визначення номіналу монети

Після зчитування всіх кіл на зображенні програма припускає, що це є монети та виявляє найбільшу з них, порівнюючи їх радіуси, визначає іiі 
як монету з найбільшим номіналом відповідного класу, задає їй вже відоме значення діаметру, що відповідає номіналу. Після цього всі інші монети (кола) отримують діаметр, пропорційний їй. При пошуку кіл потрібно відштовхуватися від того, що монети будь радіусом від 25 до 100 пікселів. Діаметр монет розраховується за такою формулою:

$$
d=d_{p} \frac{d_{\max }}{d_{m \text { max }}},
$$

де $d$ - діаметр монети,

$d_{p}-$ діаметр монети у пікселях,

$d_{\max }-$ найбільший діаметр монети 3 визначеного матеріалу,

$d_{m \max }$ - діаметр найбільшої монети з визначеного матеріалу.

Знаючи справжні діаметри монет, програма співвідносить їх радіус до номіналу згідно офіційних даних, наведених на сайті Національного Банку України на інформаційній сторінці щодо розмінних та обігових монет України. Реалізація методу пошуку кіл на зображенні:

- зображення стискається до потрібних розмірів;

- створюється копія зображення для відображення на ній результату роботи програми;

- виконується попередня обробка зображення, застосовується чорно-білий фільтр і розмиття по Гаусу.

Сніпет методу пошуку кіл на зображенні: def main(image, material="): $\mathrm{d}=1024$ / image.shape[1] $\operatorname{dim}=(1024, \operatorname{int}($ image $\cdot \operatorname{shape}[0] * d))$ image $=\mathrm{cv} 2$.resize(image, dim, interpolation $=\mathrm{cv} 2$. INTER_AREA) output $=$ image.copy () gray $=\mathrm{cv} 2 . \mathrm{cvtColor}($ image, $\mathrm{cv} 2$. COLOR BGR2GRAY) gray $=\mathrm{cv}$.medianBlur(gray, 15) if material $==$ ": clf, score $=$ get_classifier() rows $=$ gray.shape $[0]$ circles $=\mathrm{cv} 2$.HoughCircles

(gray, cv2.HOUGH_GRADIENT, 1, rows / 10, param $1=50$, param $2=23$, minRadius $=25$, maxRadius $=100$ )

Метод визначення діаметру кіл представлено на наступному сніпеті. Спочатку знаходиться найбільший радіус, який буде відповідати найбільшому номіналу (його істинний діаметр вже відомий), а потім інші.

Сніпет методу визначення діаметру кола:

\author{
def scale(coin_list : list): \\ biggest coin $=\max ($ coin_list, \\ key $=$ lambda item: item.d) \\ scale_coef $=1$

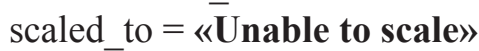 \\ if biggest_coin.material $==\langle$ gold $»$ : \\ scale_coef $=26 /$ biggest_coin.d \\ scaled_to = «Scaled to 1 UAH (old)» \\ elif biggest_coin.material $==$ «silver»: \\ scale_coef $=20.2$ / biggest_coin.d \\ scaled to $=$ «Scaled to 2 UAH» \\ for coin in coin list: \\ coin.d $*=$ scale_coef \\ return scaled_to
}

Метод обробки POST-запиту можна переглянути на наступному сніпеті. Метод дістає передане вхідне зображення зі змінної request. 3 зображення формується масив NumPy та передається далі для формування масиву зображення фреймворку OpenCV, не змінюючи вхідних параметрів зображення. Далі використовується метод отримання зображеннярезультату, яке кодується у base64 для динамічного відображення на головній сторінці додатку.

Сніпет обробки POST-запиту:

@app.route('/detect', methods=['GET', 'POST']) def $\operatorname{detect}()$ :

if request.method $==$ 'POST':

$\mathrm{f}=$ request.files.get('coin')

mode $=$ request.form.get $($ 'mode')

img_array $=n p . \operatorname{array}($ bytearray $($ f.read $)$,

Dtype $=$ np.uint 8$)$

img $=\mathrm{cv} 2$.imdecode(img_array,

cv2.IMREAD_UNCHANGED)

detected_coins $=$ dc.main $(\mathrm{img}$, material $=$ mode $)$

cv2.imwrite('temp.jpg', detected_coins)

with open('temp.jpg', «rb»)

as img_file: image_data $=$ base64.b64encode $(\mathrm{img}$ file.read()).decode('utf-8')

data_url = 'data: image/jpg; base64,' + image_data return data_url return 'not a post request'

Після аналізу буде відображена вся необхідна інформація: всі знайдені монети будуть підсвічені, в їх центрі буде надпис із номіналом, у лівому нижньому куті буде прописана загальна кількість монет і їх сума.

Результати застосування перетворення Хафа до зображення представлено на Рисунках 4 (монети жовтого кольору) та Рисунок 5 (монети різного кольору). Ідентифікацію можна проводити для кожного кольору монет як окремо, так і разом. 


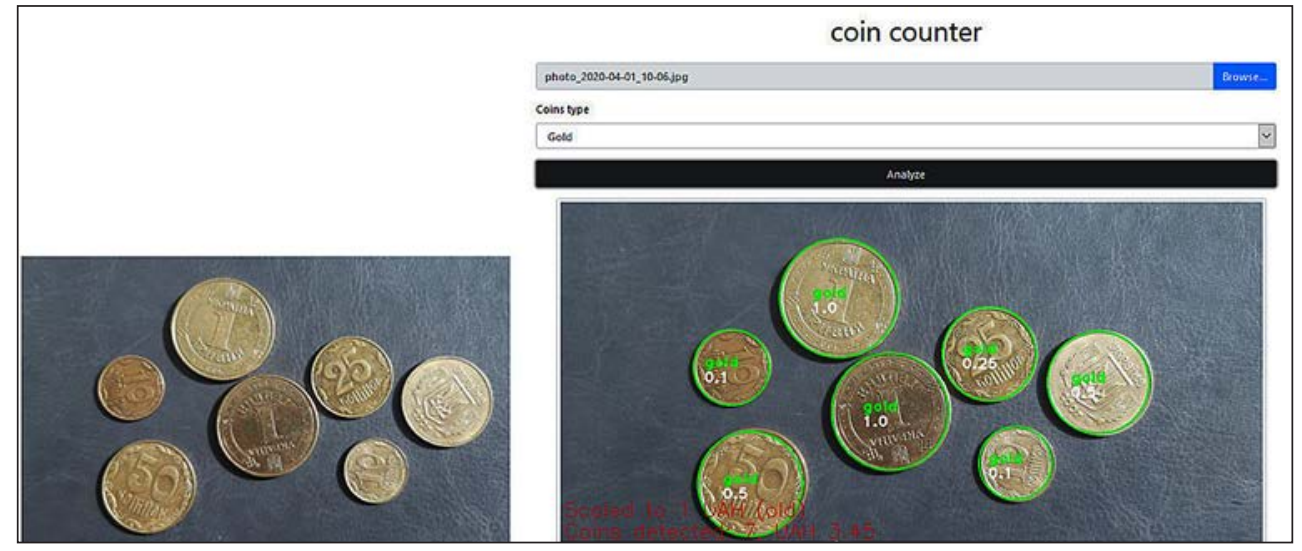

Рис. 4. Зображення монет жовтого кольору до і після ідентифікації

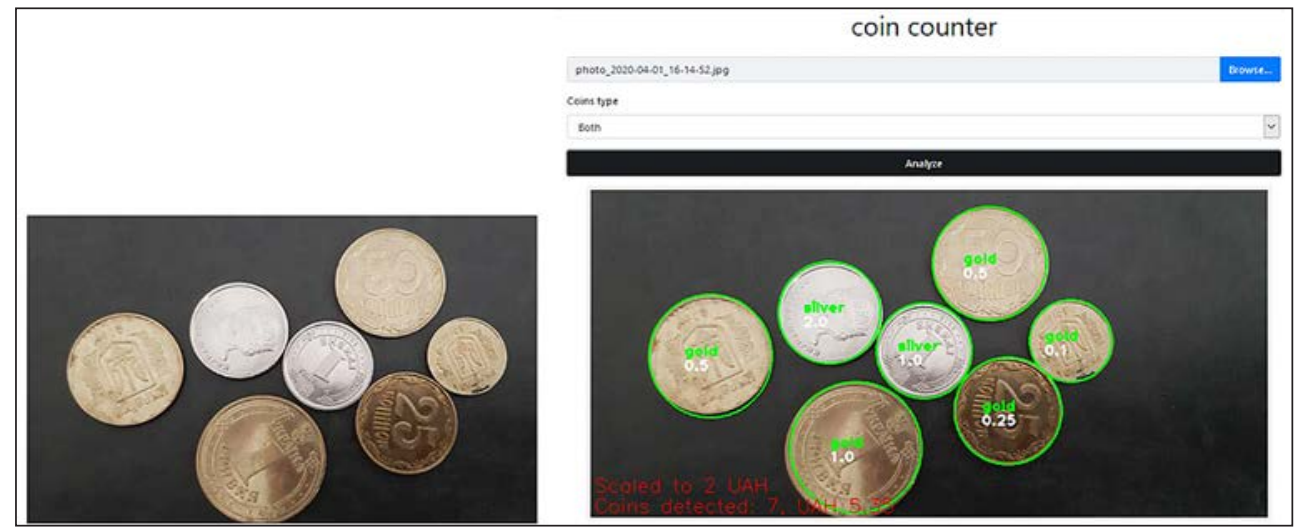

Рис. 5. Зображення монет різного кольору до і після ідентифікації

Висновки. Програмний додаток дозволяє порахувати суму змішаних між собою монет, використовуючи фотографію; розпізнає монети номіналом одна, дві, п'ять, десять, двадцять п'ять і п'ятдесят копійок, одна гривня старого зразка та одна і дві гривні нового зразка.
Отримані результати показують, що запропонований метод може бути використаний для того, щоб визначати кольори (золотий, срібний), номінал монет (одна, дві, п’ять, десять, двадцять п'ять копійок, одна і дві гривні) та проводити розрахунок суми всіх представлених монет. Правильна ідентифікація монет досягнута у $82,21 \%$ випадків.

\section{Список літератури:}

1. Yip R. Modification of hough transform for circles and ellipses detection using a 2-dimensional array / R. Yip, P. Tam, D. Leung. // Pattern Recognition. 1992. № 9. C. 1007-1022.

2. Huber-Mörk R. Automatic Coin Classification and Identifi- cation [Електронний ресурс] / R. HuberMörk, M. Rubik, M. Nölle. 2012. Режим доступу до peсурсу: https://cdn.intechopen.com/pdfs/36682/InTechAutomatic_coin_classification_and_identification.pdf. DOI: 10.5772/35795.

3. Jain N. Coin Recognition Using Circular Hough Transform / N. Jain, N. Jain. // International Journal of Electronics Communication and Computer Technology. 2012. C. 101-104.

4. Преобразование Хафа, его обобщения и модификации. [Електронний ресурс]. 2008. Режим доступу до ресурсу: http://wiki.technicalvision.ru/index.php/Преобразование_Хафа_для_поиска_окружностей.

5. Bradski G. Learning OpenCV: Computer vision with the OpenCV library / G. Bradski, A. Kaehler. Sebastopol, California, USA : O’Reilly Media, Inc., 2008. 571 c.

\section{Marchuk G.V., Lysogor Iu.I., Myslyvyi M.V. COMPUTER VISION IN RECOGNITION OF UKRAINIAN COINS OF DIFFERENT DENOMINATION}

The article deals with the recognition method of small coins of different size, color and denomination that have been removed from cash circulation of Ukraine. The aim of the research is to create a software application to determine coins denomination, number and total sum using computer vision. It requires object 
detection technologies using OpenCV library. One of the most effective methods of finding analytically given primitives is Hough transform based methods. Huff transformation is a method of straight and curved lines detection in halftone or color images.

The method enables a curves family parameters specification and provides a search on the image of the set of curves of a given family. The paper considers the algorithm of finding circles in the image. The general algorithm of the software application is to determine the type of coins in the image. All Ukrainian coins are available in silver and gold. Silver coins include one, two, five denomination coins made of stainless steel or aluminum alloy. Gold coins are ten, twenty-five, fifty, one hryvnia denomination coins made of brass. Coins radius is determined by the algorithm with respect to raw material.

Information on circulation coins diameter is taken from the website of the National Bank of Ukraine. Correct coins identification is $82,21 \%$. The coin recognition and counting mechanisms proposed could be used in various financial institutions. The software application allows you to estimate the amount of coins of small denominations using a photo. It can also recognize coins of different denominations and colors of old and new designs.

Key words: coin, computer vision, algorithm, circle, analysis. 